\title{
Colorectal cancer derived organotypic spheroids maintain essential tissue characteristics but adapt their metabolism in culture
}

\author{
Uros Rajcevic ${ }^{1,3,7}$, Jaco C Knol ${ }^{2}$, Sander Piersma ${ }^{2}$, Sébastien Bougnaud ${ }^{1}$, Fred Fack', Eirik Sundlisaeter ${ }^{4}$,
} Karl Søndenaa ${ }^{6}$, Reidar Myklebust ${ }^{5}$, Thang V Pham ${ }^{2}$, Simone P Niclou ${ }^{1}$ and Connie R Jiménez ${ }^{2^{*}}$

\begin{abstract}
Background: Organotypic tumor spheroids, a 3D in vitro model derived from patient tumor material, preserve tissue heterogeneity and retain structural tissue elements, thus replicating the in vivo tumor more closely than commonly used 2D and 3D cell line models. Such structures harbour tumorigenic cells, as revealed by xenograft implantation studies in animal models and maintain the genetic makeup of the original tumor material. The aim of our work was a morphological and proteomic characterization of organotypic spheroids derived from colorectal cancer tissue in order to get insight into their composition and associated biology.

Results: Morphological analysis showed that spheroids were of about $250 \mu \mathrm{m}$ in size and varied in structure, while the spheroid cells differed in shape and size and were tightly packed together by desmosomes and tight junctions. Our proteomic data revealed significant alterations in protein expression in organotypic tumor spheroids cultured as primary explants compared to primary colorectal cancer tissue. Components underlying cellular and tissue architecture were changed; nuclear DNA/ chromatin maintenance systems were up-regulated, whereas various mitochondrial components were down-regulated in spheroids. Most interestingly, the mesenchymal cells appear to be substantial component in such cellular assemblies. Thus the observed changes may partly occur in this cellular compartment. Finally, in the proteomics analysis stem cell-like characteristics were observed within the spheroid cellular assembly, reflected by accumulation of Alcam, Ctnnb1, Aldh1, Gpx2, and CD166. These findings were underlined by $\mathrm{IHC}$ analysis of Ctnnb1, CD24 and CD44, therefore warranting closer investigation of the tumorigenic compartment in this 3D culture model for tumor tissue.
\end{abstract}

Conclusions: Our analysis of organotypic CRC tumor spheroids has identified biological processes associated with a mixture of cell types and states, including protein markers for mesenchymal and stem-like cells. This 3D tumor model in which tumor heterogeneity is preserved may represent an advantageous model system to investigate novel therapeutic approaches.

Keywords: Colorectal cancer, Tissue spheroids, Proteomics, Mass spectrometry, Cancer stem cells, Bioinformatics, Cancer biomarkers, Label-free proteomics, 3D cell cultures

\footnotetext{
*Correspondence: c.jimenez@vumc.nl

${ }^{2}$ OncoProteomics Laboratory, Department of Medical Oncology,

VUmc-Cancer Center Amsterdam, VU University Medical Center, De Boelelaan

1117, 1081 HV Amsterdam, the Netherlands

Full list of author information is available at the end of the article
} 


\section{Background}

Preclinical cancer research has thrived on in vitro culturing systems. However, it has become increasingly clear that long term monolayer cultures used to study molecular and biological aspects of tumor cells, as well as their response to therapeutic agents, have lost a great many features exhibited by in vivo tumors. In cell monolayers, the architecture of a tumor tissue and the complex connections and interactions of its constituent cell types and matrix molecules are largely lost, intratumoral differences in nutrition, oxygenation, and drug penetration are abrogated, and growth on a plastic substratum can induce significant changes in cellular genotype and phenotype.

In contrast, three-dimensional cell culture systems have biological characteristics which are more closely related to those of in vivo tissue [1-4]. Spherical, multicellular aggregates called spheres can be grown from established cell lines or dissociated tissue cells in serum-free medium containing appropriate growth factors [5-9]. In recent years, sphere growth has become the basis of clonogenicity assays used to score for cancer stem cell-like cells (CSC). The latter are thought not only to underlie spheroid growth in vitro, but also to fuel tumor growth (and recurrence) in vivo, producing a similarly heterogeneous progeny of more differentiated cell types in both cases. Self-renewing at a relatively slow rate, CSCs are assumed to maintain an undifferentiated, damage-, apoptosis- and drug-resistant compartment of tumorinitiating cells. Thus, in contrast to their differentiated progeny, CSCs are clonogenic in vitro and tumorigenic in vivo, and therefore appear to be the main culprits in cancer biology. However, stem cell (-like) behavior may be a dynamic rather than a static property, i.e. a feature that can be adopted by more differentiated cells through interactions with the stromal environment [10] and/or through epithelial-mesenchymal transition (EMT) processes [11]. The Lgr5-positive crypt base columnar cell was suggested to represent the stem cell of the small intestine and colon [12]. It has also been described for normal colon biology that the transfer of stem cells between the border and central regions of crypts, endows all Lgr5+ colon stem cells with long-term self-renewal potential through which a heterogeneous cell population is able to function long term as a single stem-cell pool [13]. In mice, the Lgr5-expressing colon stem cells depend on stem cell niche signals provided by a specialized daughter cell, the (CD24+)Paneth cell $[14,15]$. The colon CSC compartment maintenance may depend on equivalent niche signals.

Detailed cellular and molecular characterization of CSCs, including their specific protein expression profiles, may lead to a better understanding of tumor biology, and provide novel biomarkers and targets for therapeutic procedures. Different markers have been proposed for the identification of colorectal CSCs, including CD133 (Prominin-1), CD166 (Alcam), CD44, EpCAM, CD24, CD29 (Integrin beta-1) and others [16] as well as the Lgr5 protein found in normal intestinal stem cells [16-21]. In addition to these cell surface markers, the use of intracellular markers involved in epithelial development and differentiation has been proposed to identify CSCs [22-24]. For example, Wnt signaling cascades, where nuclear b-catenin is one of the key players (reviewed in [16]), have important roles in the homeostatic self renewal of the intestine as well as in colorectal carcinogenesis. Thus, their role in colorectal cancer 'stemness' has received particular attention [25-27].

Spheroids can not only be generated from (dissociated) cultured cells, but also directly from tissue biopsy fragments in an organ culture type of fashion [28-32]. Importantly, these "tumor tissue spheroids" preserve tissue characteristics of the original tumor in situ that are not only lost in monolayer cultures of cell lines, but also in spheroids derived from dissociated tissue cells. Specifically, tissue elements such as extracellular matrix, capillaries, connective tissue, and immune cells can be demonstrated in such 'organotypic' spheroids as well as tumor cell heterogeneity [28]. These tissue spheroids still preserve tumor-initiating potential as demonstrated by xenografting experiments in animal models, where they generated stem-like tumor phenotype [33]. Moreover, in case of glioblastoma, the spheroids themselves display some features of stemness evident in the expression of certain markers and cell growth patterns [33]. In addition to that, in colorectal cancer research tissue culture protocols were reported that allow the isolation and propagation of tumor-derived 3D-spheroid/organoid cultures that are enriched in CSCs $[19,23,34,35]$. It is also well known that genomic profiles of long term cell cultures frequently deviate from parental tumor profiles, whereas spheroids are genetically more stable and representative of the original tumor [36]. Therefore, with a complexity that is lower than that of the original tumor, but higher than that of other in vitro culture systems, organotypic tissue spheroids could be used to maintain and study tumor-like tissue and test therapeutic agents in vitro in a more relevant setting. Recently, successful 3D culture system was also described that allows long-term expansion of adult small intestine, stomach and liver cells without the need of a mesenchymal niche, while preserving the characteristics of the original adult epithelium [37-39] using the Wnt agonist RSPO1 in culture medium [40-43].

Here, we have established colorectal carcinoma (CRC) spheroid cultures from patient resection material. These spheroids develop into an outer layer of epithelial-like cells and an inner core of mesenchymal-like cells. To characterize the spheroid-specific protein repertoire and 
to assess the similarities between spheroids and biopsies at the protein level, we have performed an in-depth differential proteomics analysis of CRC tissue spheroids versus the original tissue resection material from which they were derived. To the best of our knowledge, this is the first in-depth proteomics characterization of primary tumor (tissue) spheroids that includes identification and relative quantification of a significant set of proteins on a high-end mass spectrometric platform. Biological network and pathway analysis of proteins that were differential between tumor spheroids and their parental tumors indicate that nuclear (chromatin, DNA, and RNA regulatory) proteins, cytoskeletal and cell-cell/cell-substratum interaction proteins, are up-regulated, whereas mitochondrial and metabolic processes are clearly down-regulated. Although harboring a mixed population of cells and their associated cellular processes, organotypic spheroids show elevation of a number of putative markers associated with CSCs, such as oxidative stress-induced proteins like Aldh1 and Gpx2, and the cell surface marker CD166 (Alcam1) and b-catenin. Therefore this system may prove relevant for drug testing and yield novel drug targets and markers for further testing in pre-clinical animal models.

\section{Results and discussion}

\section{Tumor spheroid formation}

We have generated tumor tissue spheroids from human colorectal tumor resection material. Of 12 colon adenocarcinomas studied, 11 formed spheroids, usually after 2-5 days in culture. In contrast, normal colonic mucosa always failed to form spheroids in culture. The number of spheroids formed from each tumor depended on the amount of biopsy material, but generally the number of spheroids was over 30 . Only tissue fragments that formed spherical aggregates within 5 days in culture were used for further study. Spheroid size varied between $150-350 \mu \mathrm{m}$ in diameter and average size was about $250 \mu \mathrm{m}$ (Figure 1A). The spheroids from three (Table 1; highlighted CC9, 11, 12) colon adenocarcinomas that were further analyzed remained stable in size over time in a 20-day culturing period. Also, when comparing spheroids from different patients, no significant difference in spheroid size could be discerned (Additional file 1: Figure S1A).

\section{Microscopical and immunohistochemical characterization of tumor spheroids}

Scanning electron microscopy of tumor tissue spheroids revealed a somewhat variable spheroid structure, ranging from a largely smooth surface (Figure 1A) to a more blebby appearance (Figure 1B). This variation was observed even for spheroids derived from the same tumor. Also, structures that seemed to be the remnants of a vessel were present on the surface of one spheroid (not shown). On a higher SEM magnification (Figure 1C), small scale 'brush' structures can be seen on the spheroid surface. In transmission electron microscopical images, these structures were observed at the surface of peripheral cells (Figure 1D), with a rather irregular shape and thickness (see higher magnification in Figure 1E). This suggests that these cells preserve, to some extent, a polarized epithelial-like character. TEM revealed a considerable variation in shape and size of spheroid cells, which were closely interconnected and joined by desmosomes (1E large arrow) and tight junctions (Figure 1F, arrowhead). Characteristically, the nuclei were hyperchromatic and large, and the cytoplasm showed unusual high numbers of vacuoles and structures similar to lysosomes (Figure 1D).

Figure 2 shows H\&E stainings as well as immunohistochemical characterization of CRC tissue biopsies and biopsy-derived spheroids. Generally, as observed in TEM, in H\&E-stained sections spheroid cells were tightly packed together (Figure 2A, B). Interestingly spheroids often resumed a $3 \mathrm{D}$ structure that was reminiscent of the intestinal tissue organization with an outer layer of cells, one to five cells thick that seemed to be of an epithelial nature. The epithelial character was confirmed by staining for cytokeratin 20 (CK20/Krt20), an established marker for colonic epithelial cells (Figure 2C, D). In contrast, CK20 staining was undetectable in the central core of spheroids. The converse was true for the mesenchymal marker, vimentin (Vim), which was detected in the central core, but not in the epithelial-like layer (Figure 2E, F). To assess proliferative activity, spheroids were stained for the proliferation marker, Ki-67/Mki67 (Figure 2G, H). Whereas the proliferation index was calculated to be $51.6 \%$ for tumor tissue, it was only $5.5 \%$ within spheroids indicating that 10-day-old organotypic tumor spheroids contain few cycling cells (Additional file 1: Figure S1B), which is consistent with the absence of spheroid growth over time. Figure 2I, J also shows an example of tumor infiltrating immune cells, as revealed by staining for the macrophage-associated CD68 marker, that could still be found in spheroids (Figure 2J, suggesting that the organotypic spheroid culture model still retains non-neoplastic cells of the tumor microenvironment and thus approximates the in vivo situation more than monolayer cultures or monoclonal spheroids do. Given the cellular ratio of epithelial-like versus mesenchymal-like cells, it is to be expected that whole-spheroid analyses will be dominated by the latter.

\section{Differential proteomics of CRC tumor tissue and CRC tissue spheroids}

To assess relative differences in protein expression between CRC tumor tissue and organotypic spheroids derived thereof, lysates of tumor tissue as well as corresponding 


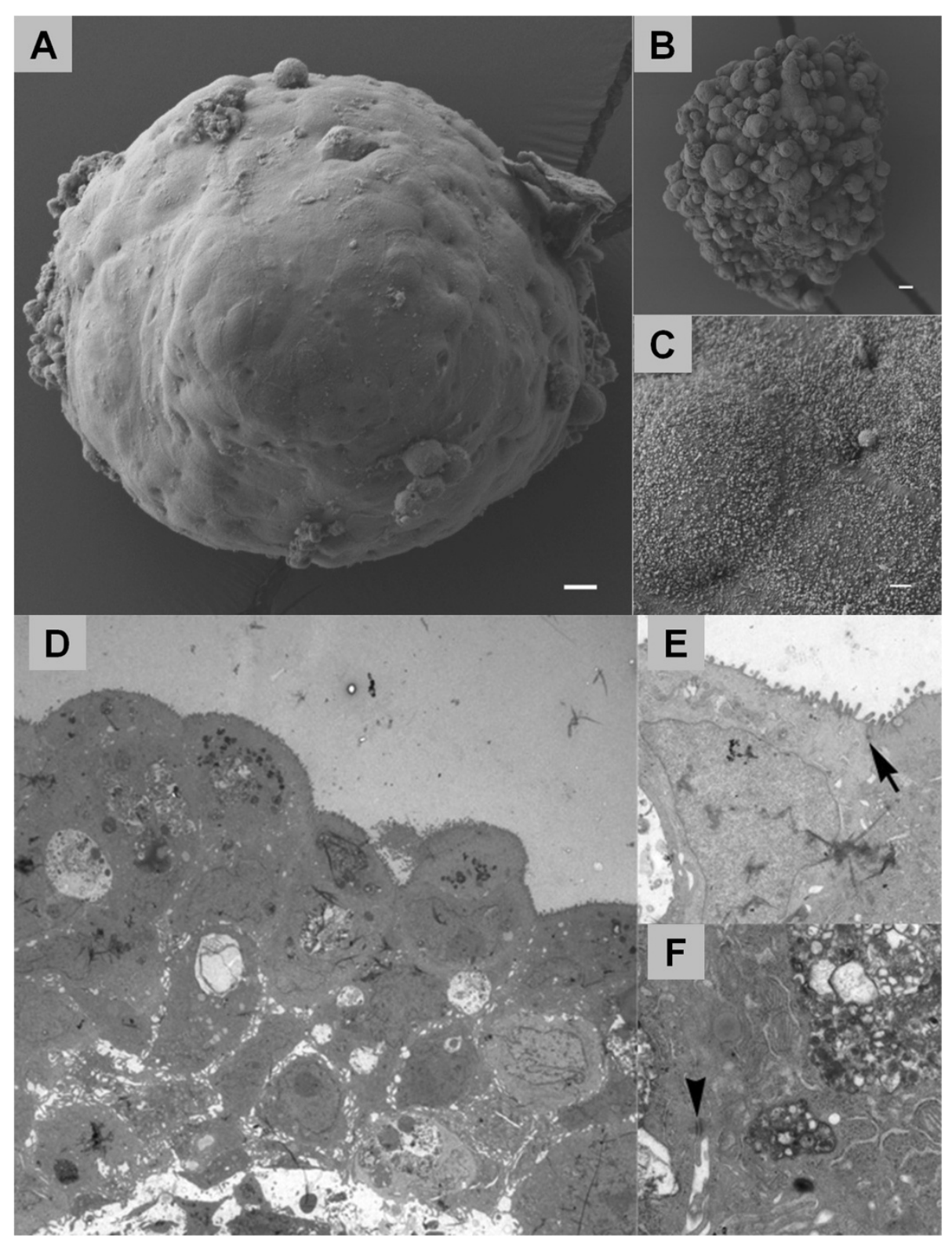

Figure 1 Electron microscopy showing ultrastructure of the colorectal cancer spheroids under investigation. Scanning electron

micrograph of spheroids grown from different tumors (A, B) showing variation in surface architecture. Scale bars $=10 \mu \mathrm{m}$. The presence of microvilli was revealed on greater magnification (C). Scale bar $=1 \mu \mathrm{m}$. (D-F) Transmission electron microscopy. Transmission electron micrograph from a spheroid after 10 days of culture (D). Note the nuclear pleomorphism indicating tumor cell heterogeneity, and the presence of microvilli (small arrow) at the apical surface of peripherally located cells (E). Cells were closely interrelated; tight junctions (large arrow) in (E) and desmosome junctions (arrowhead) were observed between neighboring cells (F). Magnification: D; 2000x, E; 12000x and F; 15000x.

spheroids were prepared with material from three patients. We set out to fractionate similar protein amounts from each lysate on an SDS-PAGE gel (Additional file 2: Figure S2), process individual gel slices through in-gel tryptic digestion, and analyze the resultant tryptic peptide mixtures using label-free nanoLC-MS/MS. Subsequently, we performed database searching and spectral counting as described before $[44,45]$ to discern relative differences in protein expression between different samples.
Our analysis yielded a dataset of 1366 IPI database entries (1315 unique proteins) that were identified across all samples (see Materials and Methods for identification criteria). In each group, the overlap of protein identification across all three biological samples was over 50\% (Additional file 3: Figure S3). The majority (1133) of the 1315 proteins (86\%) was found in both tumor tissue and spheroids, whereas a minority was specific to either sample type (Figure 3A). This suggests a high similarity 
Table 1 Clinical patient data and corresponding colorectal carcinoma samples grown as spheroids in vitro

\begin{tabular}{llllll}
\hline Patient \# & Gender & Age & Tumor localization & TNM Stage (I-IV) & Spheroid formation \\
\hline $\mathbf{1}$ & M & 65 & Distal & III & Yes \\
$\mathbf{2}$ & F & 48 & Distal & II & Yes \\
$\mathbf{3}$ & F & 73 & Distal & II & Yes \\
$\mathbf{4}$ & M & 83 & Distal & III & Yes \\
$\mathbf{5}$ & F & 81 & Proximal & II & No \\
$\mathbf{6}$ & M & 69 & Proximal & III & Yes \\
$\mathbf{7}$ & M & 74 & Distal & II & Yes \\
$\mathbf{8}$ & F & 82 & Distal & III & Yes \\
$\mathbf{9}$ & M & $\mathbf{5 2}$ & Proximal & Y & Yes \\
$\mathbf{1 0}$ & M & 85 & Distal & III & Yes \\
$\mathbf{1 1}$ & $\mathbf{F}$ & $\mathbf{5 6}$ & Proximal & Distal & Yes \\
$\mathbf{1 2}$ & $\mathbf{F}$ & $\mathbf{4 7}$ &
\end{tabular}

Samples of patients 9, 11, 12 (highlighted in red) were used for proteomics.

between spheroids and parental tumor tissue. Differential details of the dataset are shown in Figure 3B. A subset of 174 proteins exhibited $>1.5$-fold change in each of the pairs, and 105 proteins of those additionally exhibited a more than twofold difference between tumor tissues and spheroids (70 up-regulated, 35 down-regulated) (Figure 3B). A supervised cluster analysis using these 174 differential proteins is shown in a heat map view in Figure 3C. Two main clusters are discerned, corresponding to the CRC tissue samples and the tissue spheroid samples, respectively. The up-regulated proteins contained a subset of 26 acute phase, coagulation, and complement cascade proteins (Additional file 4: Table S1) that are at least partly introduced by the medium used for spheroid culturing, and were therefore not subjected to further analysis. The remainder of the differentially expressed proteins are listed in Tables $2 \mathrm{~A}, 2 \mathrm{~B}, 3 \mathrm{~A}$ and $3 \mathrm{~B}$. The whole dataset is provided in Additional file 5: Table S2.

Our proteomics data indicate an accumulation in mesenchymal-like cells (as deduced from the twofold up-regulation of the mesenchymal marker vimentin) and a decrease in epithelial-like cells (as deduced from the overall down-regulation of several markers: cytokeratin 20, mucin 2 (Muc2), and vilin 1 (Vil1)) in spheroids as detailed in Additional file 5: Table S2). Epithelial markers such as E-cadherin (Cdh1) see also (Figure 4) and Epcam appear to be relatively unchanged. Loss of the former is associated with tumor progression and invasion [46], whereas the latter has been associated with the colonic cancer stem cell (Co-CSC) compartment [19]. The far






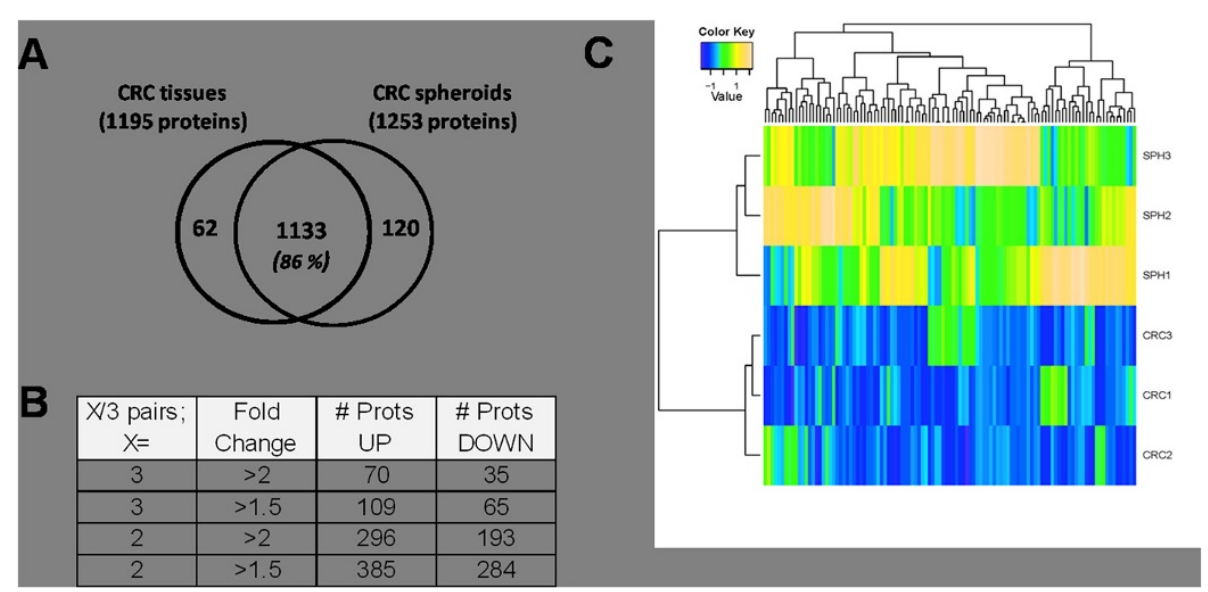

Figure 3 Summary of the protein expression data in colorectal tumors vs corresponding spheroids. (A) Venn diagrams illustrating overlapping sets of unique proteins identified in CRC tissues and CRC spheroids derived thereof. (B) Tables denoting the number of differential proteins, respectively, with different criteria for filtering. Abbreviations: CRC, colorectal tumor tissue; SPH, CRC spheroids; FC, fold change; Sp. Count separated, number of proteins from the third column $(p<0.05$ \& FC $>2)$ that, in addition, exhibit spectral count separation: the lowest spectral count in one group is higher than the highest spectral count in the other group. (C) Heat map view of a supervised cluster analysis using differential proteins from the comparison CRC tissue and spheroid proteomes (174 proteins with 1.5 fold change in all 3 pairs). The protein abundances were normalized to zero mean and unit variance for each protein. Two clusters are formed for the CRC tissue lysate and spheroid groups. CRC, colorectal cancer; tissue sample; SPH, spheroid sample.

majority of the regulated proteins reported in Table $1 \mathrm{~A}$ (68 of 70) have a ratio of $\sim 3$ and higher while vimentin is upregulated in spheroids only with a Fc of 1.9 (Table 2B, 3B). Therefore, the differential expression of most proteins in our top list cannot be solely explained by the epithelial/ stroma ratio.

\section{Protein network analysis for differential proteins}

To obtain a first impression of the type (s) of regulated proteins that are functionally interconnected in our dataset, we fed the lists of Tables 2 and 3 to the web-based STRING tool [47], which mines known and predicted protein interactions. These networks were imported and visualized in Cytoscape [48] (Figures 5 and 6), and associated biological functions were explored using the BINGO plugin for Cytoscape [49]) (Additional file 6: Table S3). In the network of proteins up-regulated in spheroids (Figure 5), one can discern [1] a set of proteins involved in translation (Rpl11, Rpl21, Eif3i, Eif4h,
Eef1b2); [2] a characteristic RNA splicing factor network involved in binding, metabolism, and processing of nuclear RNA (e.g., Hnrnpa0, Srsf3, Ddx17); [3] a layer of interacting proteins involved in chromatin anchoring and epigenetic/transcriptional regulation (Cbx3, Cbx5, Set, Ilf3), DNA replication (Set, Pcna), or DNA repair (Parp1, Pcna); [4] two interconnecting heat shock proteins (HSPA4 and HSPB1) [5] a set of components involved in cytoskeletal organization, organelle organization, cell-cell interactions, and signal transmission, including Vim, talins (Tln1, Tln2), the anti-mitogenic protein Rap1A, Rac1, and Zyx; [6] tissue development proteins (including Tagln, Csrp2, Rac1); and [7] a set of proteins involved in nitrogen compound metabolism (PpIa, Tpi1, Mdh1, Nit2, Dpysl3)).

At a lower stringency level, by including proteins upregulated in spheroids in at least two out of three sample pairs (Additional file 7: Table S4), further support is obtained for an increase in: RNA splicing factors and proteins involved in DNA replication, nucleosome reorganization

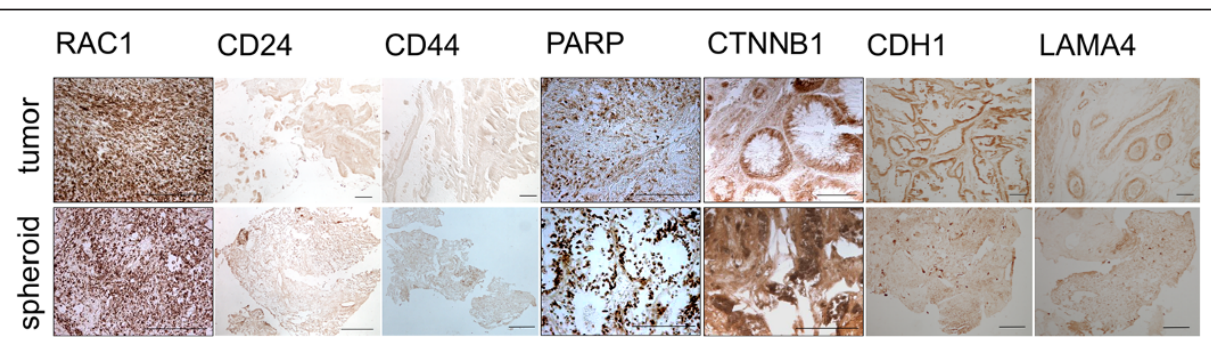

Figure 4 Immunohistochemical staining of CRC biopsies and corresponding spheroids. The section shows mainly the internal, mesenchymal part of the spheroid. Scale bar is $100 \mu \mathrm{m}$ for all images. 


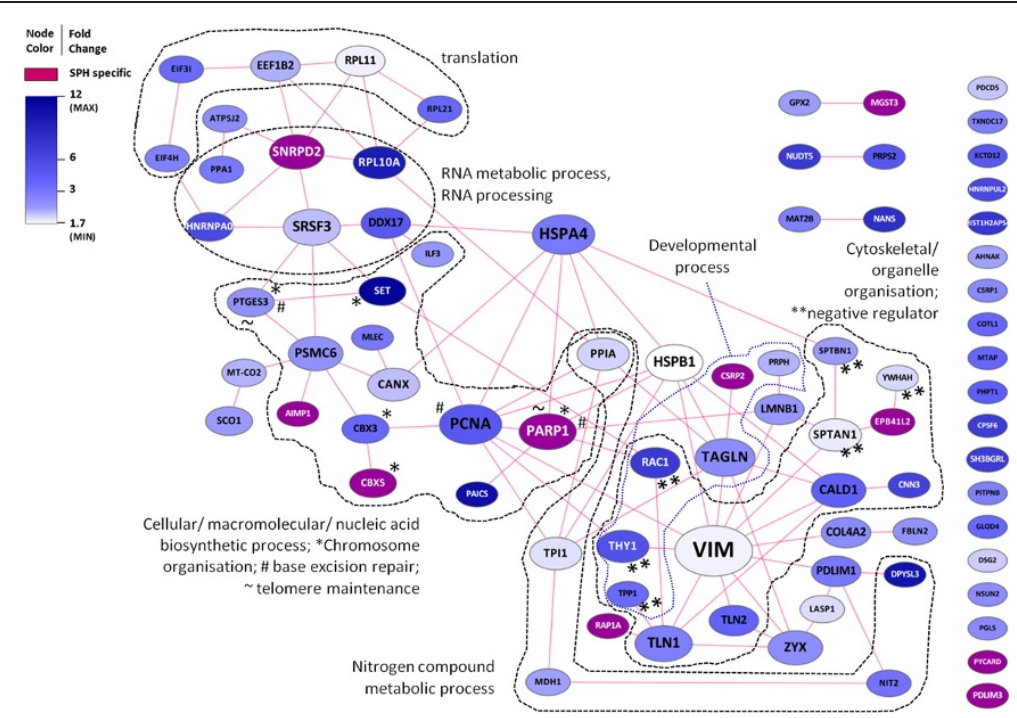

Figure 5 Network of up-regulated proteins (referenced by gene symbols) in all CRC-SPH pairs. Proteins up-regulated with a fold change > 1.5 in all three pairs of spheroids (SPH) versus their parent colorectal carcinoma tissue (CRC) were pre-screened with the BINGO gene ontology tool, and inflammatory/acute phase-related proteins were deleted from the list. The remaining proteins were uploaded to STRING, and the returned protein-protein link data were used to generate and annotate a protein network in Cytoscape. Nodes and their labels were sized according to the number of edges connected to them. Node color was made dependent on the overall fold change in all three CRC-SPH pairs: nodes exhibiting a defined fold change were colored along a white-to-blue gradient (minimum and maximum values indicated), whereas nodes only detected in SPH were colored purple, see color legend.

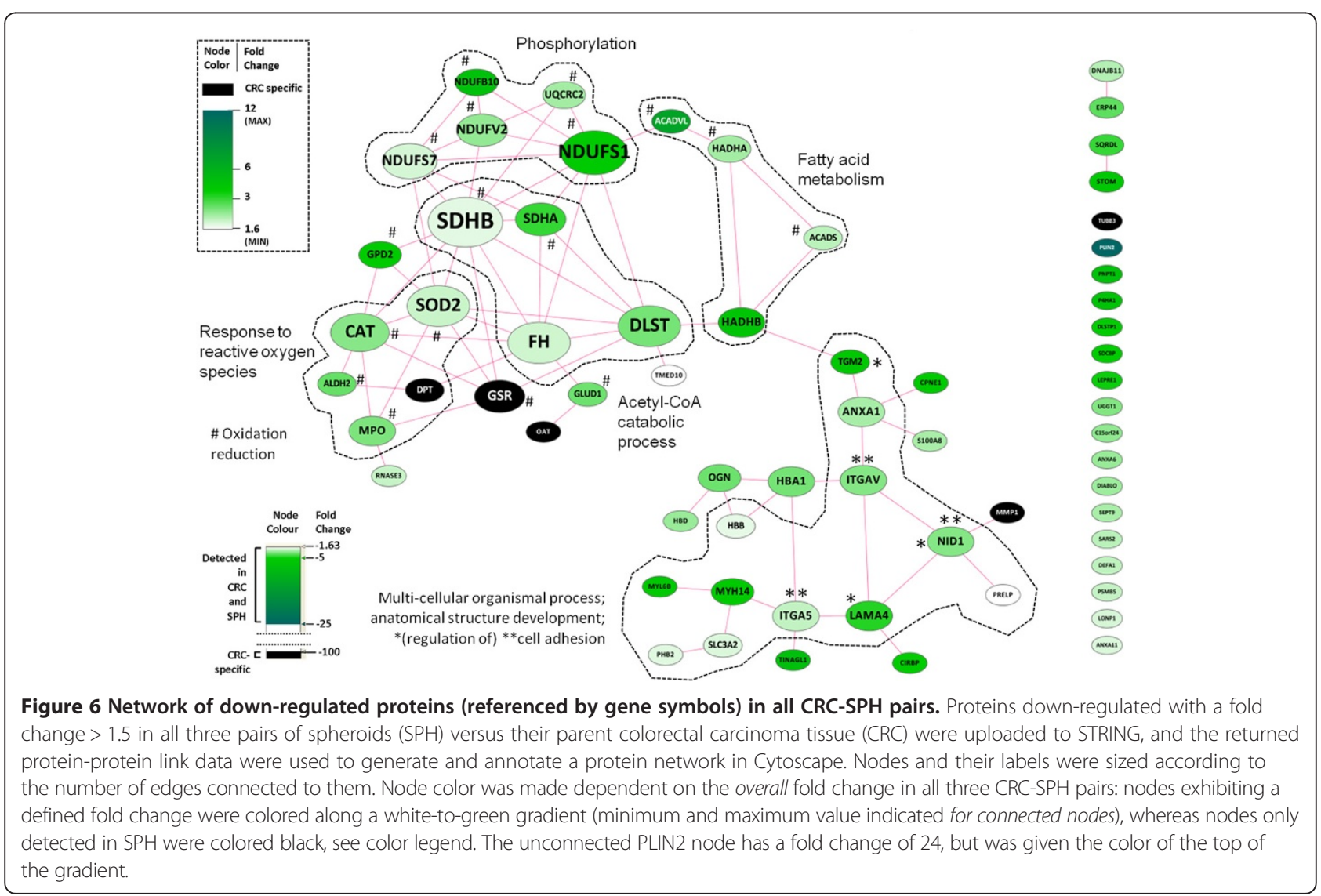


and transcription (Mcm3, Mcm7, Ssrp1), several additional nuclear lamina/scaffold proteins (Lmnb1, Emd, Matr3, Numa1, Ncl), proteins involved in shuttling between the cell cortex/focal adhesions and the nucleus ( $\delta$-catenin (Ctnnd1), Lpp, Ahnak), and the central Wnt pathway effector $\beta$-catenin (Ctnnb1). The latter protein has been strongly implicated in 'stemness' of both normal and cancer stem cells of the colon. Among the set of up-regulated proteins in $\geq 2 / 3$ pairs (Additional file 7: Table S4), we also discern proteins involved in reducing cellular stress (Hsph1, Gsto1, Gstm1, Gpx2, Aldh1a1). The latter two proteins have been recently associated with, and proposed as markers for, colonic CSCs [23].

Among the (core of) down-regulated proteins (Figure 6), there is a preponderance of interconnected mitochondrial enzymes involved in phosphorylation, fatty acid metabolism, acetyl-CoA catabolism, and responses to reactive oxygen species. This correlates with a reduced metabolic rate, in particular a reduction in cell proliferation and in oxidative phosphorylation, which is in agreement with the slow cycling activity and the reduced oxygen tension present in the spheroids. Some of the down-regulated proteins are involved in reducing oxidative stress (Cat, Sod2, Gsr), whereas others may contribute to such stress (e.g. mitochondrial respiratory chain components) or apoptosis (Tgm2). Overall mitochondrial activity seems to be significantly reduced, although, interestingly, and against the trend, both cytochrome c oxidize (Mt-co2) and one of its biosynthetic chaperones (Sco1) are up-regulated. In addition, a set of proteins associated with anatomical structure development involving cell-substratum interactions and extracellular matrix composition/modulation are down-regulated (Lama4, Myl6b, Itga5, Phb2, Itgav, Tgm2, Anxa1, Nid1, Hbb, Prelp). In all, the nature of the downregulated proteins suggests a reduction of mitochondrial activity and a change in the cell-substratum interface, going from CRC tumor tissue to spheroids in vitro. Furthermore, the down-regulation of the Mpo peroxidase seems to indicate a relative depletion of immune cells in spheroids.

\section{Immunohistochemistry of selected spheroid-enriched proteins}

The expression of a number of proteins encountered in the above charts has been further characterized through immunohistochemical staining (Figure 4). These proteins include the nuclear protein Parp1 involved in DNA repair (Figure 4), and the nuclear and/or cytoplasmic Wnt pathway components $\beta$-catenin and Rac1 implicated in stemness (Figure 4). As expected these proteins could be confirmed both in spheroids and the tumor biopsies, further supporting the similarities between the samples. Similar expression of Cdh1 in tissue vs spheroids as found by proteomics was confirmed by IHC staining (Figure 4). The proposed markers of cell stemness CD44 and CD24 were also included in the IHC analysis and showed slight increase in spheroids (Figure 4). Finally, the downregulation of the cell-cell-interaction protein LAMA4 in the spheroids as determined by proteomics was confirmed by IHC (Figure 4), possibly indicating a more fluid organization of ECM and cell-cell interactions in spheroids.

\section{Functional implications of tumor spheroid analyses}

Being able to study tumorigenic cells in their native niche, but ex vivo, is invaluable for gleaning information about basic cancer biology and tumor cell resistance, as well as for early in vitro testing of new candidate anti-tumor drugs. Although monolayer (2D) cultures of established cell lines and spheroid (3D) cultures of both tumor cell lines and dissociated tumor tissue cells have provided us with useful information, these models are of monoclonal origin and have lost the complexity of a heterogeneous cancer tissue. Organotypic spheroids such as used here, which preserve multicellularity throughout the procedure and retain original tissue elements [28], more closely resemble the tissue in vivo. Such structures harbor tumor initiating cells, as revealed by xenograft implantation studies in animal models [33]. According to the CSC concept, such cells should exhibit characteristics linked with ordinary stem cells, such as slow cycling [50], enhanced DNA repair, chromatin maintenance and telomerase activity [51], resistance to (oxidative) stress and apoptosis [52-55], and drug detoxification and efflux (Additional file 5: Table S2) [50]. Here, we have performed an initial proteomic characterization of organotypic spheroids derived from CRC tissue, which, following in vitro culture, appear to be enriched in stem-like cells, while maintaining the cellular complexity of the parental tumor.

The CRC tumor spheroids as grown here, exhibit at least a dichotomy of cell types: the outer surface is made up of epithelial-like cells, whereas the inner core contains substantial part of mesenchymal-like cells recapitulating the tissue of origin. The observed ultrastructural variability (Figure 1A and B) might be explained by a differential extent of (outer) extracellular matrix deposition/ remodeling, a process that according to our proteomics data is ongoing in spheroids relative to parental tumor tissue. Indeed, as the generation of spheroids from primary tissue will be accompanied by significant changes in cell and tissue architecture, it is not unexpected that various proteins associated with the extracellular matrix, the cell cortex, and the cellular cytoskeleton are found upregulated in spheroids (see Tables 2 and 3, Figures 5 and 6). Apart from these changes, we observe up-regulation of specific proteins associated with protein translation, RNA metabolism (RNP components), and DNA/chromatin/chromosome organization and maintenance, as well as down-regulation of a significant set of mitochondrial proteins.

Ki-67 staining suggests that very little proliferative activity occurs in spheroids. When we inspect our differential 
proteomics data on up-regulated proteins, we encounter the Pcna protein and the Mcm proteins, all classically implicated in DNA replication. However, the above molecules may serve more complex functions. Thus, $\mathrm{Mcm}$ proteins are stably loaded onto chromatin in the G1 phase, but require triggering of their helicase activity and ensuing replication to unload; following replication arrest, they remain bound indefinitely [56]. Pcna, a binding partner for a plethora of proteins, and subject to diverse post-translational modifications, has been dubbed the "maestro of the replication fork", and is involved in multiple processes including, besides DNA replication, DNA repair, chromatin remodeling, sister-chromatid cohesion, and cell cycle control $[57,58]$. These proteins may accumulate in cell cycle arrested cells and thus, replication does not necessarily have to be the major differential DNA/chromatin-associated process when comparing CRC tumor tissue with the spheroids grown from that tissue.

Indeed, it seems that the nuclear proteins upregulated in spheroids form part of a larger array of proteins involved in chromatin regulation/maintenance as well as DNA repair. Cbx proteins have been classically associated with epigenetic repression of gene expression (binding to histone $\mathrm{H} 3$ in silenced chromatin), although they also seem to have a role in transcription $[59,60]$. Furthermore, they are known to connect chromatin to the nuclear lamina through the lamin $B$ receptor [61]. In our dataset, in the lower stringency analysis, Cbx3 (also known as HP1 $\gamma$ ) and Cbx5 (also known as HP1 $\alpha$ ) are both connected to the histone H3f3a variant (H3.3) which is not only linked with active gene transcription [62], but also with heterochromatin formation [63], and possibly lineage priming in mesenchymal stem cells [64]. Moreover, histones H2a (a nucleosome constituent) and HIST2H2BE Hist2h2be (both upregulated in two out of three spheroid samples) play an important role (may contribute to the formation of the functional antimicrobial barrier of the colonic epithelium) in epigenetic control of stem cells [65]. It remains however, to be analyzed whether the chromatin-modification reflects a changing stress response. Furthermore, the Set protein has been linked with inhibition of both HAT-dependent transcription [66] and DNA demethylation [67], thus enhancing gene silencing. Set is also an anti-apoptotic component involved in caspase-independent apoptosis. Another multifaceted protein that is upregulated in spheroids is the DNA repair protein Parp1 $[68,69]$. One of the additional roles of Parp1 is induction of repressed chromatin [70], and it has also been associated with telomere maintenance [71].

One of the nuclear spheroid proteins that warrants follow-up studies as a candidate prognostic and drug resistance biomarker in CRC is ILF3. ILF3 was also identified as spheroid enriched protein in our previous proteomics screen of single cell-derived CRC spheres [72]. This protein is a double-stranded RNA (dsRNA) binding protein that complexes with other proteins, dsRNAs, small noncoding RNAs, and mRNAs to regulate gene expression and stabilize mRNAs, and has an emerging function in DNA repair. In translational studies, ILF3 was part of a gene signature that can predict survival in lung cancer patients which is relevant for the selection of patients for adjuvant therapy [73]. In the latter study, ILF3 showed correlated mRNA and protein overexpression in lung cancer development and progression. In another study, ILF3 was part of a gene expression pattern for doxorubicin (Adriamycin) resistance where resistant breast tumors highly expressed this gene [74]. In all, it appears that CRC tissue spheroids harbor chromatin maintenance and DNA repair processes that are enhanced to some degree.

When inspecting the proteins that are down-regulated in spheroids versus CRC tumor tissue, one is immediately struck by the widespread down-regulation of mitochondrial proteins, including multiple respiratory chain components. Reprogramming of energy metabolism is an emerging hallmark of cancer cells [75], and tumor cell metabolism a relatively new focus of attention [76]. Metabolic reprogramming in response to hypoxia is associated with several well-known regulators implicated in cancer biology, including p53, PI3K, NFKB, HIF1, and Myc [77]. In this light it is of note that loss-of-function mutations of fumarate hydratase (Fh) and succinate dehydrogenase $(\mathrm{Sdh})$ components (down-regulated in our study, Figure 6) have been associated with certain tumors, and that the resulting accumulation of fumarate or succinate can counter the destruction of Hif1a [76]. Also, reduced conversion of acetyl-CoA (see Figure 6) may make this key intermediary available for histone acetyl transferases that mark the genome epigenetically [78]. Shunting glucose into the pentose phosphate pathway instead of mitochondrial oxidative phosphorylation allows cells to generate NADPH, a key molecule in anti-oxidant defense [76]. The concomitant down-regulation of anti-oxidant proteins such as Sod2 and Gsr (as well as peroxisomal Cat) may be overcome by sufficient dampening of mitochondrial activity, as well as by the up-regulation of oxidative stress-reducing proteins such as Mgst3 [79], and Gpx2 [24]. Other proteins that we found to be differential may also contribute to the detoxification of harmful compounds, such as Nit2 [80], Cbr1, Aldh1a1, as well as other up-regulated dehydrogenases in our dataset (Additional file 5: Table S2) [81,82]. In relation to these defense mechanisms, cell survival through inhibition of apoptosis might also occur. Here, we see a somewhat mixed picture: whereas pro-apoptotic molecules such as Pycard, and Pdcd5 exhibit elevated levels, anti-apoptotic proteins such as Set and Hspb1 
are up-regulated, in addition to the down-regulation of death-inducing proteins such as Diablo and Tgm2. The latter protein is normally squelched by Gstp1 $[83,84]$, a protein which is slightly up-regulated in our dataset. Mitochondrial alterations may also affect the role these organelles normally play in cellular apoptosis [85]. Together, our observations suggest that CRC tumor spheroids try to ward off various forms of cellular stress, including hypoxia.

We have detected increased levels of $\beta$-catenin (Ctnnb1) a key component of the classical Wnt pathway [86,87], in our spheroids (Additional file 7: Table S4). Both Parp1 and Xrcc6 (also known as Ku70), proteins found in our dataset to be up-regulated in spheroids, can bind to the Tcf4/ $\beta$ catenin transcription factor complex central to Wnt signaling $[88,89]$. Since $\beta$-catenin has turned out to be a hallmark protein defining "Wnt activity" and "stemness" in colorectal stem cells and CSCs $[10,86]$, one would surmise that tumor spheroids, harboring tumor-initiating cells, contain cells that display such activity. However, "Wnt activity" is determined by nuclear localization of the $\beta$-catenin protein $[10,86]$, the extent of which we cannot assess from our data.

In recent years, attempts have been made to characterize (and sort) tumorigenic, colorectal CSCs through cell surface markers such as CD133 (Prom1), CD166 (Alcam), CD44, EpCAM, CD29 (Itgb1), and CD24 [17,18,21,22]. Especially the CD133 marker has received much focus [18,19], but has become somewhat controversial [90], and concerns have been raised regarding the antibody used to detect the CD133 antigen [91]. Of the above, in our proteomics study, we have only detected Alcam as a differential protein in 2 of 3 tissue-spheroid pairs, in addition to CD44, which was only differential in one pair. We did, however, also observe significantly differential levels for the intracellular Aldh1a1 and Gpx2 proteins which were recently associated with the colorectal CSC compartment $[23,24]$. In line with the above, the IHC analyses of putative colorectal tumor stem cell markers showed increased expression of Ctnnb1, CD24 and CD44 in spheroids vs tumors by IHC (Figure 4) thus indicating the presence of a cancer stem cell compartment.

\section{Conclusions}

In sum, collectively our data reveal significant similarities between organotypic CRC spheroids and primary CRC tumor tissue. The differences detected at the protein level include components underlying cellular and tissue architecture; an upregulation of nuclear DNA/ chromatin maintenance systems and a down-regulation of various mitochondrial components in spheroids. In view of the substantial content of mesenchymal cells in such cellular assemblies, these changes may largely occur in this compartment. We have also observed some stem cell-like characteristics within the mix of different cell types and cell states present in spheroids, including Alcam, Aldh1, Gpx2, Ctnnb1, CD24, CD44, and CD166 warranting closer investigation of the tumorigenic compartment in this 3D culture model for tumor tissue as well as the use for in vitro drug testing.

\section{Patients, materials and methods \\ Patient tumor material}

Tumor fragments were obtained after surgery from 12 patients with colorectal carcinoma (Table 1). All the tumors were classified histologically as adenocarcinomas by a pathologist. Consent was given by the patients for the use of the tissue for experimental purposes, and investigations were approved by the ethical committee of the Haukeland University Hospital, Bergen, Norway. The specimen obtained at surgery were immediately transferred aseptically to a test tube containing growth medium: Dulbecco's modified Eagle's medium supplemented with $10 \%$ fetal calf serum (FCS), four times the prescribed concentration of nonessential amino acids, $4 \mathrm{mM} \mathrm{L}$-glutamine, penicillin $(100 \mathrm{IU} / \mathrm{ml})$, streptomycin $(100 \mu \mathrm{g} / \mathrm{ml})$ and Fungin ${ }^{\mathrm{Tm}}(10 \mu \mathrm{g} / \mathrm{ml})$ (Bio Whittaker, Verviers, Belgium).

\section{Cell culture and spheroid growth}

Specimen selected for three-dimensional (spheroid) culture were cut, minced, and incubated in $75-\mathrm{cm}^{2}$ agarcoated tissue culture flasks (Nunc, Roskilde, Denmark) with $30 \mathrm{ml}$ growth medium (described above). The growth medium was changed every second day. After 2-5 days of culture in a standard tissue culture incubator $\left(5 \% \mathrm{CO}_{2}, 100 \%\right.$ air humidity), the tissue fragments formed multicellular spheroids. Following 5 days of culture, individual spheroids (150 to $500 \mu \mathrm{m}$ in diameter) from 12 different patients were transferred with a sterile Pasteur pipette from the culture flasks into $16-\mathrm{mm}$ agar-coated multiwell dishes with $2 \mathrm{ml}$ growth medium. Spheroid size was estimated during a period of 20 days, using an inverted microscope with a calibrated reticle in the eyepiece. All further experiments, including proteomics were performed after 10 days of culture.

\section{Electron microscopy}

Five spheroids from three tumors were collected, in each case, for transmission electron microscopy (TEM) or scanning electron microscopy (SEM) study. Spheroids were fixed for 3 hours in $2 \%$ glutaraldehyde in $0.1 \mathrm{M}$ sucrose-adjusted cacodylate buffer $(\mathrm{pH} 7.4 ; 300 \pm$ $10 \mathrm{mOsmol}$ ). Post fixation was performed for 1 hour in $1 \%$ $\mathrm{OsO}_{4}$ using the same buffer. The specimens were dehydrated with ethanol in concentrations increasing to $100 \%$.

For TEM, embedding in Epon 812 was performed by using graded additions of Epon-propylenoxide mixtures. 
The final polymerization was carried out at $60^{\circ} \mathrm{C}$ for 3 days. Sections (60 nm thick) were cut with a diamond knife on a Reichert Ultracut E ultramicrotome (Leica, Buffallo, NY), collected on 200-mesh copper grids, and examined in a Jeol 1230 transmission electron microscope (Jeol, Tokyo, Japan) operated at $80 \mathrm{kV}$.

For SEM, the specimens were critical-point dried with $\mathrm{CO}_{2}$. They were then carefully mounted on stubs using tape and silver conductive paint. The specimens were coated with gold in a vacuum evaporator and examined with a Jeol JSM -7400 F Scanning Electron Microscope (Jeol, Tokyo, Japan).

\section{Light microscopy and immunohistochemistry}

Part of collected material (Table 1) was routinely fixed for 48-72 hours (tumor tissue) or 12-24 hours (spheroids) in $4 \%$ formaldehyde solution, and embedded in paraffin. 5- $\mu \mathrm{m}$ - sections were hematoxylin and eosin $(\mathrm{H} \& \mathrm{E})$ stained for light microscopical investigation.

For immunohistochemical (IHC) analyses, all blocking and staining materials were from Dako (Glostrup, Denmark) unless stated otherwise. Paraffin sections were dewaxed and rehydrated. The slides were heated in a microwave oven for $2 \mathrm{~min}$ at $1000 \mathrm{~W}$, then $18 \mathrm{~min}$ at $200 \mathrm{~W}$, in citrate buffer for antigen retrieval. Endogenous peroxidase activity was blocked with peroxidase block for $10 \mathrm{~min}$. After washing with Tris-buffered saline (TBS) for $3 \times 3 \mathrm{~min}$, protein block was applied for $20 \mathrm{~min}$, followed by primary antibodies for $45 \mathrm{~min}$ in a humid chamber at room temperature and sections were washed for $3 \times 3$ min with TBS. Envision system was used for visualization of antibody binding, with 3,3'diaminobenzidine (DAB) as a chromogen. All sections were then counterstained with haematoxylin and mounted with Entellan mounting medium (Merck, Darmstadt, Germany).

The following antibodies and dilutions were used: anticytokeratin 20, 1:20 (Genetex, San Antonio, TX, USA), anti-vimentin, 1:100 (Dako, Glostrup, Denmark), antiCD68, 1:50 (Dako, Glostrup, Denmark), anti-podoplanin, 1:100 (Acris, Hiddenhausen, Germany), Ki-67, 1:100, antiPARP1, 1:100 (Bethyl, Antwerpen, Belgium), anti-Rac1, 1:50 (Chemicon, Overijse, Belgium), anti- $\beta$-catenin, 1:200 (Chemicon, Overijse, Belgium), anti-CD44 and anti-CD24, 1:50 (BD Biosciences, San Jose, CA, USA), anti-LAMA4 and anti-CDH1, 1:50 (Sigma Aldrich, Taufkirchen, Germany).

\section{Label-free proteomics by GeLC-MS/MS and spectral counting \\ Tissue lysis and gel electrophoresis}

Three pairs of CRC biopsy samples and corresponding spheroid samples (uniformly 10 days in culture) were lysed in lysis buffer (per $100 \mathrm{mg}$ tissue, one ml buffer containing $7 \mathrm{M}$ urea, $2 \mathrm{M}$ thiourea, $4 \%$ (w/v) CHAPS, and $10 \mu \mathrm{l} / \mathrm{ml}$ protease inhibitor mix (Amersham Biosciences, Piscataway, NJ, USA)). Thirty $\mu$ g protein of each sample was separated in parallel on a $10 \%$ SDS-PAGE gel. The gel was fixed and stained with Coomassie Brilliant Blue, and each gel lane was sliced in 16 pieces (see Additional file 2: Figure S2). Proteins in the gel pieces were in-gel digested, and tryptic peptides extracted, as described elsewhere [92].

\section{NanoLC-MSMS}

The nanoLC-MS/MS workflow has been described before [45]. In brief, tryptic peptide fractions were injected on a nano-LC system (Ultimate 3000, Dionex LCPackings, Amsterdam, The Netherlands) equipped with a $20 \mathrm{~cm} \times 75 \mu \mathrm{m}$ i.d.fused silica column custom packed with $3 \mu \mathrm{m} 120 \AA$ ReproSil Pur C18 aqua (Dr. Maisch, GMBH, Ammerbuch-Entringen, Germany). After injection, peptides were trapped at $30 \mu \mathrm{L} / \mathrm{min}$ on a $5 \mathrm{~mm} \times$ $300 \mu \mathrm{m}$ i.d. Pepmap C18 cartridge (Dionex LCPackings, Amsterdam, The Netherlands) at 2\% buffer B (buffer A, 0.05\% formic acid in MQ; buffer B, 80\% ACN and 0.05\% formic acid in MQ) and separated at $300 \mathrm{~nL} / \mathrm{min}$ with a $10-40 \%$ buffer B gradient in 60 min.. Eluting peptides were ionized in a Nanomate Triversa Chip-based nanospray source using a Triversa LC coupler (Advion, Ithaca, $\mathrm{NJ}$ ), and MS and MS/MS spectra were recorded on-line using an LTQ-FTICR mass spectrometer (ThermoFisher, Bremen, Germany).

\section{Data analysis}

Searching of MS and MS/MS data against version 3.31 of the human IPI (International Protein Index) database (67 511 entries), and spectral count analysis for relative quantification were performed as detailed before [45]. At the peptide level, only peptide identifications with a probability of $>95 \%$ were considered, and at the protein level, only protein identifications with a probability of $>99 \%$ and with at least two peptides identified in at least one of the samples were retained. Differential analysis of proteins in CRC tissue lysates versus corresponding spheroid lysates was performed by a pair-wise comparison of normalized spectral counts [72] where proteins with an FC $>1.5$ in each of the 3 pairs were subjected to further in silico analysis by protein network analysis and gene ontology mining (see below).

\section{Bioinformatics analysis Identifier mapping}

Using the human IPI identifiers of identified proteins, gene symbols were checked/retrieved using data from the European Bioinformatics Institute (EBI) IPI webpage (ftp://ftp.ebi.ac.uk/pub/databases/IPI) or, if the IPI identifier was no longer available in that repository, from the EBI Sequence Retrieval System (SRS) webpage 
(Present alternatives are suggested at http://srs.ebi.ac.uk) (neither of the two databases are no longer maintained) combined with a standard protein BLAST (blastp) search on the National Center for Biotechnology Information (NCBI) website (http://blast.ncbi.nlm.nih.gov). Subsequently, all gene symbols were mapped to official gene symbols using data from the HUGO Gene Nomenclature Committee (HGNC) website (http://www.genenames.org)

\section{Analysis of protein-protein interaction networks}

Lists of gene symbols associated with proteins that were up- or down-regulated, were analyzed with the Search Tool for the Retrieval of Interacting Genes/Proteins (STRING; version 8.3, http://string.embl.de). Proteinprotein interaction (PPI) data were retrieved with default settings, allowing for experimentally verified as well as predicted PPIs. The results were exported as a text file and imported in the Cytoscape network analysis and visualization tool (version 2.8.1; http://www.cytoscape. org) [48]). Nodes were colored according to FC, and sized according to the number of edges. In the case of up-regulated proteins, proteins associated with acute phase reactions coagulation, or the complement cascade, as indicated by a preliminary gene ontology analysis (see below), were removed. These proteins are listed in Additional file 4: Table S1.

\section{Gene ontology mining}

Complete networks or subclusters were analyzed within Cytoscape, using the BINGO plug-in (version 2.44; http:// apps.cytoscape.org/apps/bingo; [49]). Default settings were used (hypergeometric testing, Benjamini and Hochberg False Discovery Rate (FDR) correction, $P<0.05)$, and the whole data set was used as a reference set.

\section{Additional files}

Additional file 1: Figure 1A. Average spheroid size depending on the time in culture. Figure 1B. Proliferation Index of colorectal tumors and corresponding spheroids.

Additional file 2: Figure S2. SDS PAGE gel image showing separation pattern of tumor and corresponding spheroid proteins.

Additional file 3: Figure S3. Venn diagrams showing the overlap of protein identifications accross biological samples.

Additional file 4: Table S1. Up-regulated nodes deleted from Figure 5 (Acute phase/coaggulation/complement cascade associated).

Additional file 5: Table S2. Comparison of parental CRC tissue (CRC) vs derived spheroids (SPH) (paired samples) - All Data.

Additional file 6: Table S3A-D. Gene Ontology representation by Cytoscape and Bingo analyses.

Additional file 7: Table S4. Comparison of parental CRC tissue (CRC) vs derived spheroids (SPH) (paired samples) - Proteins exhibiting Fold Change $>1.5$-fold in at least 2 out of $3 \mathrm{CRC} / \mathrm{SPH}$ pairs.

\section{Competing interests}

The authors' declare that they have no competing interests.

\section{Authors' contributions}

UR, SPN and CRJ have made substantial contributions to conception and design of the study, analysis and interpretation of data, have been involved in drafting the manuscript, revising it critically for important intellectual content and have given final approval of the version to be published. UR, JCK, SP, SB, FF, $E S$, TVP were involved in acquisition of data, analysis and interpretation of data and in drafting the manuscript and revising it critically. KS, RM were involved in critical revision of the study and have given final approval of the version to be published. All authors read and approved the final manuscript.

\section{Acknowledgements}

This work was funded by Fonds National de Recherche (FNR) to UR and SPN, by European Commission 6th framework program (Angiotargeting project, Contract 504743); by CRP-Santé and the Research Ministry (Ministère de la Culture, de l'Enseignement Supérieur et de la Recherche) of Luxembourg and by the VU Medical Center, Cancer Center Amsterdam (to JCK, SP, TVP, and CRJ and for the proteomics infrastructure).

\section{Author details}

${ }^{1}$ NorLux Neuro-Oncology Laboratory, Department of Oncology, CRP-Santé, Luxembourg, Luxembourg. ${ }^{2}$ OncoProteomics Laboratory, Department of Medical Oncology, VUmc-Cancer Center Amsterdam, VU University Medical Center, De Boelelaan 1117, 1081 HV Amsterdam, the Netherlands.

${ }^{3}$ Department of Research and Development, Blood Transfusion Center of Slovenia, Ljubljana, Slovenia. ${ }^{4}$ Department of Biomedicine, University of Bergen, Bergen, Norway. ${ }^{5}$ Haukeland University Hospital, Bergen, Norway. ${ }^{6}$ Department of Surgery, Haraldsplass Deaconal Hospital, University of Bergen, Bergen, Norway. ${ }^{7}$ Institute of Pathology, Faculty of Medicine, University of Ljubljana, Ljubljana, Slovenia.

Received: 21 October 2013 Accepted: 9 June 2014

Published: 11 July 2014

\section{References}

1. Jacks T, Weinberg RA: Taking the study of cancer cell survival to a new dimension. Cell 2002, 111:923-925.

2. Santini MT, Rainaldi G: Three-dimensional spheroid model in tumor biology. Pathobiology 1999, 67:148-157.

3. Sutherland RM: Cell and environment interactions in tumor microregions: the multicell spheroid model. Science 1988, 240:177-184.

4. Yamada KM, Clark K: Cell biology: survival in three dimensions. Nature 2002, 419:790-791.

5. Achilli TM, Meyer J, Morgan JR: Advances in the formation, use and understanding of multi-cellular spheroids. Expert opinion on biological therapy 2012, 12:1347-1360.

6. Chong BE, Yan F, Lubman DM, Miller FR: Chromatofocusing nonporous reversed-phase high-performance liquid chromatography/electrospray ionization time-of-flight mass spectrometry of proteins from human breast cancer whole cell lysates: a novel two-dimensional liquid chromatography/ mass spectrometry method. Rapid Commun Mass Spectrom 2001, 15:291-296.

7. Labarbera DV, Reid BG, Yoo BH: The multicellular tumor spheroid model for high-throughput cancer drug discovery. Expert opinion on drug discovery 2012, 7:819-30

8. Mueller-Klieser W: Multicellular spheroids: A review on cellular aggregates in cancer research. J Cancer Res Clin Oncol 1987, 113:101-122.

9. Sutherland RM, Durand RE: Growth and cellular characteristics of multicell spheroids. Recent Result Cancer Res 1984, 95:24-49.

10. Vermeulen L, De Sousa EMF, van der Heijden M, Cameron $K$, de Jong JH, Borovski T, Tuynman JB, Todaro M, Merz C, Rodermond H, Sprick MR, Kemper K, Richel DJ, Stassi G, Medema JP: Wnt activity defines colon cancer stem cells and is regulated by the microenvironment. Nat Cell Biol 2010, 12:468-476.

11. Mani SA, Guo W, Liao MJ, Eaton EN, Ayyanan A, Zhou AY, Brooks M, Reinhard F, Zhang CC, Shipitsin M, Campbell LL, Polyak K, Brisken C, Yang J, Weinberg RA: The epithelial-mesenchymal transition generates cells with properties of stem cells. Cell 2008, 133:704-715.

12. Barker $N$, van Es JH, Kuipers J, Kujala P, van den Born M, Cozijnsen M, Haegebarth A, Korving J, Begthel H, Peters PJ, Clevers H: Identification of stem cells in small intestine and colon by marker gene Lgr5. Nature 2007 449:1003-1007. 
13. Ritsma L, Ellenbroek SI, Zomer A, Snippert HJ, de Sauvage FJ, Simons BD Clevers $\mathrm{H}$, van Rheenen J: Intestinal crypt homeostasis revealed at single-stem-cell level by in vivo live imaging. Nature 2014, 507:362-365.

14. Sato T, Clevers $\mathrm{H}$ : Growing self-organizing mini-guts from a single intestinal stem cell: mechanism and applications. Science 2013, 340:1190-1194.

15. Sato T, Katagiri K, Gohbara A, Inoue K, Ogonuki N, Ogura A, Kubota Y, Ogawa T: In vitro production of functional sperm in cultured neonatal mouse testes. Nature 2011, 471:504-507.

16. Vaiopoulos AG, Kostakis ID, Koutsilieris M, Papavassiliou AG: Colorectal cancer stem cells. Stem Cells 2012, 30:363-371.

17. Dalerba P, Dylla SJ, Park IK, Liu R, Wang X, Cho RW, Hoey T, Gurney A, Huang EH, Simeone DM, Shelton AA, Parmiani G, Castelli C, Clarke MF: Phenotypic characterization of human colorectal cancer stem cells. Proc Natl Acad Sci U S A 2007, 104:10158-10163.

18. O'Brien CA, Pollett A, Gallinger S, Dick JE: A human colon cancer cell capable of initiating tumour growth in immunodeficient mice. Nature 2007, 445:106-110.

19. Ricci-Vitiani L, Lombardi DG, Pilozzi E, Biffoni M, Todaro M, Peschle C, De Maria R: Identification and expansion of human colon-cancer-initiating cells. Nature 2007, 445:111-115.

20. Munoz J, Stange DE, Schepers AG, van de Wetering M, Koo BK, Itzkovitz S, Volckmann R, Kung KS, Koster J, Radulescu S, Myant K, Versteeg R, Sansom OJ, van Es JH, Barker N, van Oudenaarden A, Mohammed S, Heck AJ, Clevers $\mathrm{H}$ : The Lgr5 intestinal stem cell signature: robust expression of proposed quiescent '+ 4' cell markers. EMBO J 2012, 31:3079-3091.

21. Vermeulen L, Sprick MR, Kemper K, Stassi G, Medema JP: Cancer stem cells-old concepts, new insights. Cell Death Differ 2008, 15:947-958.

22. Lassmann S, Opitz OG: The new look of colorectal cancer stem cells. Gastroenterology 2008, 134:1262-1264.

23. Emmink BL, Van Houdt WJ, Vries RG, Hoogwater FJ, Govaert KM, Verheem A, Nijkamp MW, Steller EJ, Jimenez CR, Clevers H, Borel Rinkes $\|_{\text {, Kranenburg }}$ $\mathrm{O}$ : Differentiated human colorectal cancer cells protect tumor-initiating cells from irinotecan. Gastroenterology 2011, 141:269-278.

24. Naiki-lto A, Asamoto M, Hokaiwado N, Takahashi S, Yamashita H, Tsuda H, Ogawa K, Shirai T: Gpx2 is an overexpressed gene in rat breast cancers induced by three different chemical carcinogens. Cancer Res 2007, 67:11353-11358

25. Espina C, Cespedes MV, Garcia-Cabezas MA, del Pulgar MT G, Boluda A, Oroz LG, Benitah SA, Cejas P, Nistal M, Mangues R, Lacal JC: A critical role for Rac1 in tumor progression of human colorectal adenocarcinoma cells. Am J Pathol 2008, 172:156-166

26. Fodde $\mathrm{R}$, Brabletz T: Wnt/beta-catenin signaling in cancer stemness and malignant behavior. Curr Opin Cell Biol 2007, 19:150-158.

27. Reya T, Clevers H: Wnt signalling in stem cells and cancer. Nature 2005, 434:843-850.

28. Bjerkvig R, Tonnesen A, Laerum OD, Backlund EO: Multicellular tumor spheroids from human gliomas maintained in organ culture. J Neurosurg 1990, 72:463-475.

29. Engebraaten $\mathrm{O}$, Hjortland $\mathrm{GO}$, Hirschberg $\mathrm{H}$, Fodstad O: Growth of precultured human glioma specimens in nude rat brain. J Neurosurg 1999, 90:125-132.

30. Fehlauer F, Muench M, Smid EJ, Slotman B, Richter E, Van der Valk P, Sminia $P$ : Combined modality therapy of gemcitabine and irradiation on human glioma spheroids derived from cell lines and biopsy tissue. Oncol Rep 2006, 15:97-105.

31. Fjellbirkeland $L$, Bjerkvig $R$, Laerum OD: Tumour fragment spheroids from human non-small-cell lung cancer maintained in organ culture. Virchows Arch 1995, 426:169-178.

32. Weiswald LB, Richon S, Validire P, Briffod M, Lai-Kuen R, Cordelieres FP, Bertrand F, Dargere D, Massonnet G, Marangoni E, Gayet B, Pocard M, Bieche I, Poupon MF, Bellet D, Dangles-Marie V: Newly characterised ex vivo colospheres as a three-dimensional colon cancer cell model of tumour aggressiveness. Br J Cancer 2009, 101:473-482.

33. Sakariassen PO, Prestegarden L, Wang J, Skaftnesmo KO, Mahesparan R, Molthoff C, Sminia P, Sundlisaeter E, Misra A, Tysnes BB, Chekenya M, Peters $H$, Lende G, Kalland KH, Oyan AM, Petersen K, Jonassen I, van der Kogel A, Feuerstein BG, Terzis AJ, Bjerkvig R, Enger PO: Angiogenesis-independent tumor growth mediated by stem-like cancer cells. Proc Natl Acad Sci U S A 2006, 103:16466-16471.


Proteomics in studying cancer stem cell biology. Expert Rev Proteomics 2012, 9:325-336.
35. Sato $T$, Stange DE, Ferrante $M$, Vries RG, Van Es JH, Van den Brink S, Van Houdt WJ, Pronk A, Van Gorp J, Siersema PD, Clevers H: Long-term expansion of epithelial organoids from human colon, adenoma, adenocarcinoma, and Barrett's epithelium. Gastroenterology 2011, 141:1762-1772.

36. De Witt Hamer PC, Van Tilborg AA, Eijk PP, Sminia P, Troost D, Van Noorden CJ, Ylstra B, Leenstra S: The genomic profile of human malignant glioma is altered early in primary cell culture and preserved in spheroids. Oncogene 2008, 27:2091-2096.

37. Barker N, Huch M, Kujala P, van de Wetering M, Snippert HJ, van Es JH, Sato T, Stange DE, Begthel $H$, van den Born M, Danenberg E, van den Brink S, Korving J, Abo A, Peters PJ, Wright N, Poulsom R, Clevers H: Lgr5(+ve) stem cells drive self-renewal in the stomach and build long-lived gastric units in vitro. Cell Stem Cell 2010, 6:25-36.

38. Huch M, Dorrell C, Boj SF, van Es JH, Li VS, van de Wetering M, Sato T, Hamer K, Sasaki N, Finegold MJ, Haft A, Vries RG, Grompe M, Clevers H: In vitro expansion of single Lgr5+ liver stem cells induced by Wnt-driven regeneration. Nature 2013, 494:247-250.

39. Sato $T$, Vries RG, Snippert HJ, van de Wetering M, Barker N, Stange DE, van Es JH, Abo A, Kujala P, Peters PJ, Clevers H: Single Lgr5 stem cells build crypt-villus structures in vitro without a mesenchymal niche. Nature 2009, 459:262-265.

40. Blaydon DC, Ishii Y, OToole EA, Unsworth HC, Teh MT, Ruschendorf F, Sinclair C, Hopsu-Havu VK, Tidman N, Moss C, Watson R, de Berker D, Wajid M, Christiano AM, Kelsell DP: The gene encoding R-spondin 4 (RSPO4), a secreted protein implicated in Wnt signaling, is mutated in inherited anonychia. Nat Genet 2006, 38:1245-1247.

41. Carmon KS, Gong X, Lin Q, Thomas A, Liu Q: R-spondins function as ligands of the orphan receptors LGR4 and LGR5 to regulate Wnt/beta-catenin signaling. Proc Natl Acad Sci U S A 2011, 108:11452-11457.

42. de Lau W, Barker N, Low TY, Koo BK, Li VS, Teunissen H, Kujala P Haegebarth A, Peters PJ, van de Wetering M, Stange DE, van Es JE, Guardavaccaro D, Schasfoort RB, Mohri Y, Nishimori K, Mohammed S, Heck AJ, Clevers H: Lgr5 homologues associate with Wnt receptors and mediate R-spondin signalling. Nature 2011, 476:293-297.

43. Kim KA, Kakitani M, Zhao J, Oshima T, Tang T, Binnerts M, Liu Y, Boyle B, Park E, Emtage P, Funk WD, Tomizuka K: Mitogenic influence of human R-spondin1 on the intestinal epithelium. Science 2005, 309:1256-1259.

44. Albrethsen J, Knol JC, Piersma SR, Pham TV, de Wit M, Mongera S, Carvalho B, Verheul HM, Fijneman RJ, Meijer GA, Jimenez CR: Subnuclear proteomics in colorectal cancer: identification of proteins enriched in the nuclear matrix fraction and regulation in adenoma to carcinoma progression. Mol Cell Proteomics 2010, 9:988-1005.

45. Piersma SR, Fiedler U, Span S, Lingnau A, Pham TV, Hoffmann S, Kubbutat MH, Jimenez CR: Workflow comparison for label-free, quantitative secretome proteomics for cancer biomarker discovery: method evaluation, differential analysis, and verification in serum. J Proteome Res 2010, 9:1913-1922.

46. Chen WS, Chen CC, Chen LL, Lee CC, Huang TS: Secreted heat shock protein 90alpha (HSP90alpha) induces nuclear factor-kappaB-mediated TCF12 protein expression to down-regulate E-cadherin and to enhance colorectal cancer cell migration and invasion. J Biol Chem 2013, 288:9001-9010.

47. Szklarczyk D, Franceschini A, Kuhn M, Simonovic M, Roth A, Minguez $P$, Doerks T, Stark M, Muller J, Bork P, Jensen LJ, von Mering C: The STRING database in 2011: functional interaction networks of proteins, globally integrated and scored. Nucleic Acids Res 2011, 39:D561-568.

48. Smoot ME, Ono K, Ruscheinski J, Wang PL, Ideker T: Cytoscape 2.8: new features for data integration and network visualization. Bioinformatics 2011, 27:431-432.

49. Maere S, Heymans K, Kuiper M: BiNGO: a Cytoscape plugin to assess overrepresentation of gene ontology categories in biological networks. Bioinformatics 2005, 21:3448-3449.

50. Hirschmann-Jax C, Foster AE, Wulf GG, Nuchtern JG, Jax TW, Gobel U, Goodell MA, Brenner MK: A distinct "side population" of cells with high drug efflux capacity in human tumor cells. Proc Natl Acad Sci U S A 2004 101:14228-14233.

51. Ju Z, Rudolph KL: Telomeres and telomerase in cancer stem cells. Eur J Cancer 2006, 42:1197-1203.

52. Hemmati HD, Nakano I, Lazareff JA, Masterman-Smith M, Geschwind DH Bronner-Fraser M, Kornblum HI: Cancerous stem cells can arise from pediatric brain tumors. Proc Natl Acad Sci U S A 2003, 100:15178-15183. 
53. Singh SK, Clarke ID, Terasaki M, Bonn VE, Hawkins C, Squire J, Dirks PB: Identification of a cancer stem cell in human brain tumors. Cancer Res 2003, 63:5821-5828

54. Singh SK, Hawkins C, Clarke ID, Squire JA, Bayani J, Hide T, Henkelman RM, Cusimano MD, Dirks PB: Identification of human brain tumour initiating cells. Nature 2004, 432:396-401.

55. Yuan X, Curtin J, Xiong Y, Liu G, Waschsmann-Hogiu S, Farkas DL, Black KL, Yu JS: Isolation of cancer stem cells from adult glioblastoma multiforme. Oncogene 2004, 23:9392-9400.

56. Kuipers MA, Stasevich TJ, Sasaki T, Wilson KA, Hazelwood KL, McNally JG, Davidson MW, Gilbert DM: Highly stable loading of $\mathrm{Mcm}$ proteins onto chromatin in living cells requires replication to unload. J Cell Biol 2011, 192:29-41.

57. Moldovan GL, Pfander $B$, Jentsch S: PCNA, the maestro of the replication fork. Cell 2007, 129:665-679.

58. Stoimenov I, Helleday T: PCNA on the crossroad of cancer. Biochem SoC Trans 2009, 37:605-613.

59. Kwon SH, Florens L, Swanson SK, Washburn MP, Abmayr SM, Workman JL: Heterochromatin protein 1 (HP1) connects the FACT histone chaperone complex to the phosphorylated CTD of RNA polymerase II. Genes Dev 2010, 24:2133-2145

60. Vakoc CR, Mandat SA, Olenchock BA, Blobel GA: Histone H3 lysine 9 methylation and HP1gamma are associated with transcription elongation through mammalian chromatin. Mol Cell 2005, 19:381-391.

61. Gant TM, Wilson KL: Nuclear assembly. Annu Rev Cell Dev Biol 1997, 13:669-695.

62. Ahmad K, Henikoff S: The histone variant H3.3 marks active chromatin by replication-independent nucleosome assembly. Mol Cell 2002, 9:1191-1200.

63. Santenard A, Ziegler-Birling C, Koch M, Tora L, Bannister AJ, Torres-Padilla ME: Heterochromatin formation in the mouse embryo requires critical residues of the histone variant H3.3. Nat Cell Biol 2010, 12:853-862.


Chromatin environment of histone variant $\mathrm{H} 3.3$ revealed by quantitative imaging and genome-scale chromatin and DNA immunoprecipitation. Mol Biol Cell 2010, 21:1872-1884.

65. Ohm JE, Baylin SB: Stem Cell Epigenetics. Regulatory Networks in Stem Cells. In Regulatory Networks in Stem Cells. Stem Cell Biology and Regenerative Medicine. Part III. Edited by Rajasekhar VK, Vemuri MC. New York: Humana Press; 2009:235-246.

66. Seo SB, McNamara P, Heo S, Turner A, Lane WS, Chakravarti D: Regulation of histone acetylation and transcription by INHAT, a human cellular complex containing the set oncoprotein. Cell 2001, 104:119-130.

67. Cervoni N, Detich N, Seo SB, Chakravarti D, Szyf M: The oncoprotein Set/ TAF-1beta, an inhibitor of histone acetyltransferase, inhibits active demethylation of DNA, integrating DNA methylation and transcriptional silencing. J Biol Chem 2002, 277:25026-25031.

68. Ji Y, Tulin AV: The roles of PARP1 in gene control and cell differentiation. Curr Opin Genet Dev 2010, 20:512-518.

69. Rathaus M, Lerrer B, Cohen HY: DeubiKuitylation: a novel DUB enzymatic activity for the DNA repair protein, Ku70. Cell Cycle 2009, 8:1843-1852.

70. Kim MY, Mauro S, Gevry N, Lis JT, Kraus WL: NAD + -dependent modulation of chromatin structure and transcription by nucleosome binding properties of PARP-1. Cell 2004, 119:803-814.

71. Hassa PO, Hottiger MO: The diverse biological roles of mammalian PARPS, a small but powerful family of poly-ADP-ribose polymerases. Front Biosci 2008, 13:3046-3082

72. Van Houdt WJ, Emmink BL, Pham TV, Piersma SR, Verheem A, Vries RG, Fratantoni SA, Pronk A, Clevers $\mathrm{H}$, Borel Rinkes $\mathrm{IH}$, Jimenez $\mathrm{CR}$, Kranenburg $\mathrm{O}$ : Comparative proteomics of colon cancer stem cells and differentiated tumor cells identifies BIRC6 as a potential therapeutic target. Mol Cell Proteomics 2011, 10:M111 011353.

73. Guo NL, Wan YW, Tosun K, Lin H, Msiska Z, Flynn DC, Remick SC, Vallyathan V, Dowlati A, Shi X, Castranova V, Beer DG, Qian Y: Confirmation of gene expression-based prediction of survival in non-small cell lung cancer. Clin Cancer Res 2008, 14:8213-8220.

74. Cleator S, Tsimelzon A, Ashworth A, Dowsett M, Dexter T, Powles T, Hilsenbeck S, Wong H, Osborne CK, O'Connell P, Chang JC: Gene expression patterns for doxorubicin (Adriamycin) and cyclophosphamide (cytoxan) (AC) response and resistance. Breast Cancer Res Treat 2006, 95:229-233.
75. Hanahan D, Weinberg RA: Hallmarks of cancer: the next generation. Cell 2011, 144:646-674.

76. Kroemer G, Pouyssegur J: Tumor cell metabolism: cancer's Achilles' heel. Cancer Cell 2008, 13:472-482

77. Cairns RA, Harris IS, Mak TW: Regulation of cancer cell metabolism. Nat Rev Cancer 2011, 11:85-95.

78. Bensinger SJ, Christofk HR: New aspects of the Warburg effect in cancer cell biology. Semin Cell Dev Biol 2012, 23:352-361.

79. Yang H, Dou Y, Zheng X, Tan Y, Cheng J, Li L, Du Y, Zhu D, Lou Y: Cysteinyl leukotrienes synthesis is involved in aristolochic acid l-induced apoptosis in renal proximal tubular epithelial cells. Toxicology 2011, 287:38-45.

80. Krasnikov BF, Chien CH, Nostramo R, Pinto JT, Nieves E, Callaway M, Sun J, Huebner $\mathrm{K}$, Cooper AJ: Identification of the putative tumor suppressor Nit2 as omega-amidase, an enzyme metabolically linked to glutamine and asparagine transamination. Biochimie 2009, 91:1072-1080.

81. Jakoby WB, Ziegler DM: The enzymes of detoxication. J Biol Chem 1990, 265:20715-20718

82. Yoshida A, Rzhetsky A, Hsu LC, Chang C: Human aldehyde dehydrogenase gene family. Eur J Biochem 1998, 251:549-557.

83. Nanda N, lismaa SE, Owens WA, Husain A, Mackay F, Graham RM: Targeted inactivation of Gh/tissue transglutaminase II. J Biol Chem 2001, 276:20673-20678.

84. Piredda L, Farrace MG, Lo Bello M, Malorni W, Melino G, Petruzzelli R, Piacentini M: Identification of 'tissue' transglutaminase binding proteins in neural cells committed to apoptosis. FASEB J 1999, 13:355-364.

85. Gogvadze V, Orrenius S, Zhivotovsky B: Mitochondria in cancer cells: what is so special about them? Trends Cell Biol 2008, 18:165-173.

86. Clevers H, Nusse R: Wnt/beta-Catenin Signaling and Disease. Cell 2012, 149:1192-1205.

87. Li VS, Ng SS, Boersema PJ, Low TY, Karthaus WR, Gerlach JP, Mohammed S, Heck AJ, Maurice MM, Mahmoudi T, Clevers H: Wnt Signaling through Inhibition of beta-Catenin Degradation in an Intact Axin1 Complex. Cell 2012, 149:1245-1256.

88. Idogawa M, Masutani M, Shitashige M, Honda K, Tokino T, Shinomura Y, Imai K, Hirohashi S, Yamada T: Ku70 and poly (ADP-ribose) polymerase-1 competitively regulate beta-catenin and T-cell factor-4-mediated gene transactivation: possible linkage of DNA damage recognition and Wnt signaling. Cancer Res 2007, 67:911-918.

89. Idogawa M, Yamada T, Honda K, Sato S, Imai K, Hirohashi S: Poly (ADP-ribose) polymerase- 1 is a component of the oncogenic T-cell factor-4/beta-catenin complex. Gastroenterology 2005, 128:1919-1936.

90. Shmelkov SV, Butler JM, Hooper AT, Hormigo A, Kushner J, Milde T, St Clair R, Baljevic M, White I, Jin DK, Chadburn A, Murphy AJ, Valenzuela DM, Gale NW, Thurston G, Yancopoulos GD, D'Angelica M, Kemeny N, Lyden D, Rafii $S:$ CD133 expression is not restricted to stem cells, and both CD133+ and CD133- metastatic colon cancer cells initiate tumors. J Clin Invest 2008, 118:2111-2120.

91. Kemper K, Sprick MR, de Bree M, Scopelliti A, Vermeulen L, Hoek M, Zeilstra J, Pals ST, Mehmet H, Stassi G, Medema JP: The AC133 epitope, but not the CD133 protein, is lost upon cancer stem cell differentiation. Cancer Res 2010, 70:719-729.

92. Jimenez CR, Huang L, Qiu Y, Burlingame AL: In-gel digestion of proteins for MALDI-MS fingerprint mapping. Curr Protoc Protein Sci 2001, Chapter 16:Unit 16.14. doi:10.1002/0471140864.ps1604s14.

\section{doi:10.1186/1477-5956-12-39}

Cite this article as: Rajcevic et al:: Colorectal cancer derived organotypic spheroids maintain essential tissue characteristics but adapt their metabolism in culture. Proteome Science 2014 12:39. 